\title{
PROTEÇÃO AMBIENTAL: ENTRE O DIREITO DA SUSTENTABILIDADE E O ESTADO DE COISAS INCONSTITUCIONAL
}

\author{
ENVIRONMENTAL PROTECTION: BETWEEN THE LAW OF \\ SUSTAINABILITY AND THE STATE OF UNCONSTITUTIONAL THINGS
}

Jaime Leônidas Miranda Alves*

\section{Maria Cláudia da Silva Antunes de Souza*}

RESUMO: O trabalho tem por objetivo analisar se é possível pensar na existência de um estado de coisas inconstitucional em matéria ambiental, a partir da leitura da $\mathrm{ADO} \mathrm{n}^{\circ} 60$ e da doutrina do direito da sustentabilidade. Para a realização da pesquisa foi utilizado o método indutivo na fase de investigação, somado às técnicas do referente, da categoria, dos conceitos operacionais, da pesquisa bibliográfica e do fichamento. Ao final, utilizando a ADO 60 como lócus argumentativo, pode-se concluir pela existência de um estado de coisas inconstitucional em matéria ambiental.

Palavras-chave: Ação direta de inconstitucionalidade por omissão $\mathrm{n}^{\circ} .60$. Estado de coisas inconstitucional; Jurisdição constitucional; Meio ambiente; Sustentabilidade.

\begin{abstract}
The work aims to analyze whether it is possible to think about the existence of an unconstitutional state of affairs in environmental matters, from reading the Direct Action of

\footnotetext{
* Defensor Público do Estado de Rondônia. Ex-Defensor Público do Estado do Amapá. Mestrando em Ciência Jurídica pela Universidade do Vale do Itajaí (UNIVALI). Especialista em Direito Público pela PUC-Minas. Professor no Curso de Direito da Faculdade Estácio São Paulo. Membro da Comissão de direitos do consumidor da Associação Nacional das Defensores e Defensores Público (ANADEP). Orcid: https://orcid.org/0000-00015335-2585. Endereço postal: Rua Guaporé, 5755, Centro, Rolim de Moura - RO. Endereço eletrônico: jaime_lmiranda@hotmail.com.

${ }_{*}^{*}$ Doutora e Mestre em Derecho Ambiental y de la Sostenibilidad pela Universidade de Alicante - Espanha. Mestre em Ciência Jurídica pela Universidade do Vale do Itajaí - UNIVALI. Professora Permanente no Programa de PósGraduação Stricto Sensu em Ciência Jurídica, nos cursos de Doutorado e Mestrado, e na Graduação no Curso de Direito, ambos da Universidade do Vale do Itajaí - UNIVALI. Coordenadora do Grupo de Pesquisa "Direito Ambiental, Transnacionalidade e Sustentabilidade" cadastrado no CNPq/EDATS/UNIVALI. Advogada.. E-mail: mclaudia@univali.br. Orcid: https://orcid.org/0000-0002-8118-1071. Endereço postal: Rua Dinamarca-141, Bairro Nações, Balneário Camboriú- SC. 88338-315.
} 
Unconstitutionality by omission n. 60 and the doctrine of sustainability law. In order to carry out the research, the inductive method was used in the investigation phase, added to the techniques of the referent, category, operational concepts, bibliographic research and file. Finally, using ADO 60 as an argumentative locus, it can be concluded that there is an unconstitutional state of affairs in environmental matters.

Keywords: Direct Action of Unconstitutionality by omission n. 60; State of envionmental unconstitutional things; Constitutional jurisdiction. Environment; Sustentability.

\section{INTRODUÇÃO}

A proteção ambiental é uma das maiores (senão a maior) exigências da contemporaneidade. No plano teórico, cada vez mais estudos deixam claro a necessidade de se proteger o meio ambiente, tanto para as presentes, quanto para as futuras gerações, como condição de possibilidade de permanência da espécie humana no planeta. A despeito disso, a cultura predominante ainda é pautada por um capitalismo no qual a proteção ambiental não tem vez. Em razão disso é que se justifica a presente pesquisa.

Nesse cenário, a pesquisa tem por objetivo investigar se é adequado pensar na existência, hoje, de um estado de coisas inconstitucional ambiental, especialmente à luz do julgamento da Ação Direta de Inconstitucionalidade por Omissão n. 60, em trâmite no Supremo Tribunal Federal.

Para responder à questão-problema (existe um estado de coisas constitucional ambiental?), o artigo foi dividido em três partes. A primeira traz a análise conceitual do estado de coisas inconstitucional, apresentando sua origem, tanto no âmbito da doutrina quanto da jurisprudência estrangeira, até o momento do seu reconhecimento, pelo STF, no bojo do julgamento da Arguição de Descumprimento de Preceito Fundamental nº 347.

Num segundo momento, extraem-se lições a partir da doutrina do direito da sustentabilidade, a fim de verificar se há, atualmente, um déficit de proteção ao meio ambiente ou se essa proteção é adequada, a partir da comparação entre a prática de proteção (mundo do Direito) / não proteção (mundo dos fatos) e os mandamentos constitucionais e convencionais de tutela ambiental.

Por fim, coloca-se como pano de fundo (lócus argumentativo), o teor da Ação Direta de Inconstitucionalidade por Omissão n. 60 (recebida como arguição de descumprimento de 
preceito fundamental), na qual houve alegação de omissão governamental em relação ao Fundo Clima e outras questões ambientais, enfrentadas à luz da Constituição e de compromissos internacionais firmados pelo Brasil.

Para a realização da pesquisa, elegeu-se o método indutivo na fase de investigação, somado às técnicas do referente, da categoria, dos conceitos operacionais, da pesquisa bibliográfica e do fichamento.

\section{ANTES DO MÉRITO, UM PREFÁCIO: O ESTADO DE COISAS INCONSTITUCIONAL}

O Estado de coisas constitucional é um cenário, primeiramente reconhecido na Colômbia, no qual se verificou a necessidade de intervenção da Corte Constitucional, no exercício do poder contramajoritário, a fim de garantir a proteção da dignidade de grupos vulneráveis.

Para que se reconheça a existência de um estado de coisas inconstitucional, é necessário, assim, um quadro simultâneo de a) situação de violação generalizada de direitos fundamentais; b) inércia ou incapacidade reiterada e persistente das autoridades públicas em modificar a situação; c) a superação das transgressões exigir a atuação não apenas de um órgão, e sim de uma pluralidade de autoridades (Corte Constitucional da Colômbia, Sentencia n ${ }^{\circ}$ SU-559, de 6 de novembro de 1997; Sentencia T-068, de 5 de março de 1998; Sentencia SU - 250, de 26 de maio de 1998; Sentencia T-590, de 20 de outubro de 1998; Sentencia T - 525, de 23 de julho de 1999; Sentencia T-153, de 28 de abril de 1998; Sentencia T - 025, de 22 de janeiro de 2004).

Para compreender adequadamente a ideia que gira em torno do estado de coisas inconstitucional, necessário fazer um breve comentário sobre a Sentencia SU-559, de 1997, leading case sobre o tema.

No caso em testilha, chegou ao conhecimento da Corte Constitucional colombiana o caso de 45 professores, dos municípios de María La Baja e Zambrans, que tiveram seus direitos previdenciários recusados pelas autoridades locais. Como resposta, a Corte constitucional concluiu que se tratava de uma violação generalizada de direitos, que tomava uma proporção muito superior, atingindo uma quantidade grande de pessoas, que sequer compunham o polo ativo da demanda. 
Em frente, foi reconhecida pela Corte Constitucional colombiana a existência de um estado de coisas inconstitucional, e como consequência, de um dever de colaboração existente entre todos os poderes e órgãos constitucionais a fim de suprimir esse cenário de não gozo de direitos fundamentais. No dispositivo da decisão, houve obrigação de fazer aos Ministérios da Educação e da Fazenda e do Crédito Público, à Direção do Departamento Nacional do Planejamento, aos governadores, às Assembleias legislativas, aos prefeitos e aos Conselhos Municipais, o que demonstra a necessidade de uma atuação coordenada para superar o estado de não direito.

Na sequência, a Corte Constitucional colombiana reconheceu, em outras ocasiões, estar-se diante de estado de coisas inconstitucional. Aponta Rêgo (2020) que na Sentencia T068, de 5 de março de 1998, fora declarada a mora da Caixa Nacional de Previdência em responder petições de aposentados e pensionistas que pretendiam a obtenção de novos cálculos e pagamentos de diferenças de verbas previdenciárias; com a Sentencia SU-250, de 26/5/1998, houve a determinação de realização, em âmbito nacional, de concurso público para o cargo de notário; na Sentencia T-590, de 20/10/1998, a Corte Constitucional ordenou ao Estado que pusesse em prática políticas públicas eficientes de proteção aos defensores dos direitos humanos no país; por fim, na Sentencia T-525, de 23/7/1999 agiu a Corte Constitucional colombiana no sentido de combater o atraso sistemático no pagamento de verbas de aposentadoria.

Esses são apenas alguns casos na jurisprudência colombiana, que conta ainda com precedentes veiculando matéria envolvendo deslocamento forçado de pessoas em razão da violência urbana (Sentencia T-025, de 2004) e a crise do sistema carcerário (Sentencia de Tutela T-153, de 1998).

O que esses casos apresentam em comum, segundo Campos (2015) é o fato de se tratarem de situações extremamente complexas, em que a Corte Constitucional adota um posicionamento não privativista (atuando no intuito de resolver problemas particulares, assegurando direitos específicos aos demandantes), mas, noutro giro, há uma preocupação especial na proteção da dimensão objetiva dos direitos fundamentais ${ }^{1}$.

\footnotetext{
1 Os direitos fundamentais são, a um só tempo, direitos subjetivos e elementos fundamentais da ordem constitucional objetiva. Enquanto direitos subjetivos, os direitos fundamentais outorgam aos titulares a possibilidade de impor os seus interesses em face dos órgãos obrigados. Na sua dimensão como elemento fundamental da ordem constitucional objetiva, os direitos fundamentais - tanto aqueles que não asseguram, primariamente, um direito subjetivo, quanto aqueloutros, concebidos como garantias individuais - formam a base do ordenamento jurídico de um Estado de Direito democrático (MENDES, 1999, s.p.)
} 
Campos (2015) compreende que o estado de coisas inconstitucional corresponde a uma situação de verdadeiro "litígio estrutural", ou seja, é caracterizado pela possibilidade de alcançar considerável número de pessoas, exigindo, por sua vez, para a sua separação, a criação de "remédios estruturais", demandando a atuação cooperativa de várias entidades em uma execução complexa voltada "ao redimensionamento dos ciclos de formulação e execução de políticas públicas, o que não seria possível por meio de decisões mais ortodoxas" (Campos, 2015, p. 1).

O reconhecimento do estado de coisas inconstitucional vem na tentativa de superar bloqueios desacordos políticos, possibilitando o aumento do diálogo interinstitucional, a fim de garantir a proteção de direitos fundamentais que, até então, não são concretizados ou os são de forma deficiente (untermassverbot).

O debate acerca do estado de coisas inconstitucional chegou ao Brasil em 2015, com a propositura, pelo Partido Socialista e Liberdade (PSOL) da Arguição de Descumprimento de Preceito Fundamental n. 347, proposta contra a União e todos os estados-membros.

$\mathrm{Na}$ ação, o partido indicou a existência dos pressupostos que caracterizam o estado de coisas inconstitucional no contexto do sistema carcerário brasileiro: (a) violação generalizada e sistêmica de direitos fundamentais; b) inércia ou incapacidade reiterada e persistente das autoridades públicas em modificar a conjuntura; c) situação que exige a atuação não apenas de um órgão, mas sim de uma pluralidade de autoridades para resolver o problema, pugnando pelo seu reconhecimento, pelo Supremo Tribunal Federal e, por consequência, o julgamento procedente do pedido para determinar uma série de medidas (no total, oito) para os juízes e tribunais do país, para o Conselho Nacional de Justiça e para a União.

Em decisão cautelar, o STF deferiu os pedidos referentes às audiências de custódia e à liberação as verbas do FUNPEN, tendo consignado o Ministro Marco Aurélio que "no sistema prisional brasileiro, ocorre violação generalizada de direitos fundamentais dos presos no tocante à dignidade, higidez física e integridade psíquica". Adiante, afirmou que a superlotação carcerária e a precariedade das instalações das delegacias e presídios, "mais do que inobservância, pelo Estado, da ordem jurídica correspondente, configuram tratamento degradante, ultrajante e indigno a pessoas que se encontram sob custódia" STF. Plenário. ADPF 347 MC/DF, Rel. Min. Marco Aurélio, julgado em 9/9/2015 (Info 798).

Recentemente, em sede de decisão cautelar na Ação Direta de Inconstitucionalidade por Omissão n. 60, o Ministro Roberto Barroso consignou entendimento no sentido da 
possibilidade de se pensar um estado de coisas inconstitucional em matéria ambiental, conforme se verá mais adiante.

\section{DEVERES OBJETIVOS DE PROTEÇÃO CONSTITUCIONAL E CONVENCIONAL DO MEIO AMBIENTE SOB À ÓTICA DO DIREITO DA SUSTENTABILIDADE}

Como segundo topo argumentativo, são tecidos alguns comentários acerca do meio ambiente, sob a ótica da sustentabilidade, além de apresentar os compromissos constitucionais e convencionais que compõem o dever jurídico de sua proteção.

Certo é que não há outro espaço hoje para a compreensão do dever de proteção ao meio ambiente que não o lócus argumentativo do direito à sustentabilidade. $\mathrm{O}$ direito à sustentabilidade, segundo Maria Claudia da Silva Antunes de Souza (2012), parte da compreensão de que as tragédias ambientais demonstram que o Direito ainda não é capaz de dar respostas confiáveis ao dano ambiental.

E isso é confirmado por Ferrajoli (2015) que, em Democracia através dos Direitos, afirma que crise econômica mundial se transformou em crise social, política, humanitária, ambiental, nucelar e criminal e essas crises se caracterizam por uma erosão substancial da democracia e o enfraquecimento do Estado Constitucional Moderno.

O direito da sustentabilidade exige, nessa conjectura, uma nova postura do intérprete em relação à questão ambiental. Isso porque há verdadeira relação de retroalimentação entre o meio ambiente de / sem qualidade e os demais bens jurídico-sociais. Correto o entendimento doutrinário, portanto, no sentido de que "a proteção do meio ambiente é uma questão de sobrevivência" (SOUZA, 2012, p.11).

A sustentabilidade é pensada, nessa toada, sob um aspecto multidimensional, visto que ambiental, social, econômica e tecnológica, havendo uma relação de retroalimentação entre elas (SOUZA, 2012, p. 11). Vale dizer: para que haja sustentabilidade em uma dimensão (a ambiental, por exemplo), as demais precisam estar sendo promovidas (social, econômica e tecnológica).

E toda essa proteção do meio ambiente não é mera faculdade do poder público e da sociedade. Trata-se, noutro giro, de compromisso político e jurídico de nível constitucional e 
convencional, sendo irretratável, visto que, sendo a proteção ao meio ambiente condição inafastável do direito à vida, encontra abrigo na vedação à proteção reacionária (efeito cliquet $^{2}$ ).

Com efeito, dispõe a Constituição Federal, em seu art. 225 que todos têm direito ao meio ambiente ecologicamente equilibrado, bem de uso comum do povo e essencial à sadia qualidade de vida, impondo-se ao Poder Público e à coletividade o dever de defendê-lo e preservá-lo para as presentes e futuras gerações. Não se trata de faculdade ou de diretriz, mas de mandamento constitucional, sendo vedada a proteção deficiente (untermassverbot) como imperativo da proporcionalidade.

A positivação, a nível constitucional, do dever de proteger o meio ambiente marca a superação da doutrina individualista do meio ambiente para a doutrina holística, que se iniciou com a promulgação da Lei ${ }^{\circ}$ 6.938/1981:

A esse respeito, Antônio Herman Benjamin (2007, p. 57/58):

Somente a partir de 1981, com a promulgação da Lei nº 6.938/81 (Lei da Política Nacional do Meio Ambiente), ensaiou-se o primeiro passo em direção a um paradigma jurídico-econômico que holisticamente tratasse e não maltratasse a terra, seus arvoredos e os processos ecológicos essenciais a ela associados. Um caminhar incerto e talvez insincero a princípio, em pleno regime militar, que ganhou velocidade com a democratização em 1985 e recebeu extraordinária aceitação na Constituição de 1988.

Desse modo, no plano de direito interno, há, de fato, uma consagração da proteção, no plano do direito positivo, da proteção ao meio ambiente, o que, de forma insofismável, não significa dizer que o meio ambiente é tutelado adequadamente.

No plano convencional, por sua vez, são diversos os documentos que procuram conferir normatividade e obrigatoriedade à proteção internacional do meio ambiente, podendose destacar os seguintes: i) Conferência Mundial sobre Meio Ambiente Humano (1972); ii) Relatório "Nosso Futuro Comum" (1987); iii) Conferência Mundial sobre Meio Ambiente e Desenvolvimento (Rio/92 ou Eco/92 - 1992); iv) Cúpula Mundial sobre Desenvolvimento Sustentável (Rio+10 - 2002); v) Conferência das Nações Unidas sobre Desenvolvimento Sustentável (Rio+20 - 2012.

Não há argumento jurídico, portanto, que sustente uma política de não proteção ao meio ambiente. Também, para além do direito, a partir de uma análise multidisciplinar, tal qual

\footnotetext{
${ }^{2} \mathrm{O}$ efeito cliquet apregoa a vedação ao retrocesso em matéria de direitos fundamentais, atingindo até mesmo a manifestação do Poder Constituinte originário. Assim, para quem o defende, havendo a ositivação em uma Constituição de determinado direito fundamental, não seria possível reduzir âmbito de incidência desse direito, seja por reforma à Constituição ou até mesmo por uma nova Constituição.
} 
a exigida por Edgar Morin (2003), verifica-se que a proteção do meio ambiente é condição de possibilidade e perpetuação das diversas formas de vida.

E isso é bem reafirmado por Barroso e Mello (2020, p. 331), para quem há um vínculo indissociável entre dignidade humana, direitos fundamentais, mínimo existencial e proteção ao meio ambiente, tudo desbocando na ideia de segurança humana.

A proteção ao meio ambiente é vista, então, como necessária para o gozo de três liberdades essenciais e complementares: a de não ter medo, a de não passar privações materiais e a de viver com dignidade, o que reafirma os contornos doutrinários que envolvem o direito da sustentabilidade.

Retornando ao direito da sustentabilidade, verifica-se que este é um imperativo constitucional, na medida em que traz a lume a necessidade de se pensar políticas - internas, internacionais, transnacionais, públicas e privadas ${ }^{3}$ - de proteção ao meio ambiente a partir da certeza de que esta - a proteção ao meio ambiente - é "compromisso solidário e global em prol do ambiente para assegurar, inclusive de maneira preventiva, a melhora contínua das relações entre os seres humanos e a natureza" (SOUZA, 2012, p. 11).

E essa compreensão - de proteção do meio ambiente em razão de um compromisso solidário e global com a vida - é algo que ganha novos contornos em se tratando dos povos tradicionais e de sua percepção da natureza.

\section{PENSANDO UM ESTADO DE COISAS INCONSTITUCIONAL AMBIENTAL:} ANÁLISE DA AÇÃO DIRETA DE INCONSTITUCIONALIDADE POR OMISSÃO N. 60

A proteção ambiental não constitui uma opção política, mas um dever constitucional (STF, 2020, p.2)

A Ação Direta de Inconstitucionalidade por Omissão n. 60 (ADO 60) foi proposta, em conjunto, pelo Partido Socialista Brasileiro (PSB), Partido Socialismo e Liberdade (PSOL) e

\footnotetext{
${ }^{3}$ Em termos legais, o direito de sustentabilidade é um direito pensado em termos de espécies e em termos de resolução de problemas globais. Ele traz em si a estrutura clássica dos ordenamentos jurídicos, sociais, econômicos e ambientais, que são característicos de estados soberanos, mas claramente vai além desse âmbito. Sua vocação é fornecer soluções que sirvam a todos, independentemente de onde eles são ou de onde eles nasceram. Tem por objetivo proporcionar esperança de um futuro melhor para sociedade em geral. (SOUZA, 2016. pp.245).
} 
Partido dos Trabalhadores (PT) tendo por objeto a alegação de omissão governamental em relação ao Fundo Clima, além de outras questões ambientais.

Discute-se, assim, na referida ação a existência de atos comissivos e omissivos da União que comprometeriam o adequado funcionamento do Fundo Nacional sobre Mudança do Clima (Fundo Clima), bem como o direito de todos os brasileiros a um meio ambiente saudável (CF, art. 225, caput e parágrafos).

Colhe-se da decisão cautelar que os pedidos e fundamentos coligidos pelos autores fora,: entre os atos comissivos apontados pelos requerentes, (i) a redução dos orçamentos e dotações relacionadas ao controle do desmatamento e ao fomento de formas sustentáveis de produção; (ii) o licenciamento de obras de infraestrutura, sem adequada avaliação de impacto; (iii) a desestruturação dos órgãos ambientais federais; (iv) o esvaziamento das atribuições do Ministério do Meio Ambiente; (v) a nomeação para cargos importantes de pessoas sem afinidade com a área ambiental; (vi) orientação pública para cessação da demarcação de Terras Indígenas; além de (vii) cortes orçamentários na política ambiental ainda maiores do que os que vinham ocorrendo no passado.

Por sua vez, em relação às omissões, destacam-se: (i) a falta de reuniões do Comitê Gestor do Fundo, mantido inoperante durante todo o ano de 2019; (ii) a não aprovação do Plano Anual de Aplicação de Recursos, quer para 2019, quer para 2020; (iii) a manutenção de “vultosos recursos 'em caixa' com a rubrica específica de financiar ações voltadas à mitigação de emergências climáticas".

Por fim, no que concerne ao último ponto, consta na decisão cautelar (STF, 2020) informação de que os requerentes alegam a existência de autorização orçamentária para aplicação de R \$ 8.050.000,00 não reembolsáveis para tal fim, tendo sido empenhados apenas $\mathrm{R} \$ 718.074,00$; bem como de mais $\mathrm{R} \$ 543$ milhões reembolsáveis, dos quais foram empenhados apenas R\$ 348 milhões, cujo direcionamento ao BNDES, todavia, não se concretizou. Ainda segundo os requerentes, o demonstrativo de movimentação financeira do Fundo Clima do ano de 2019 apontaria um saldo disponível de R\$ 250.074.000,00.

Consignaram cautelarmente os seguintes pedidos: suspensão do comportamento lesivo consistente em não tomar as medidas administrativas necessárias para disponibilizar os recursos relativos ao Fundo Clima; determinação de apresentação de Plano Anual de Aplicação de Recursos do Fundo para o ano de 2020 e não se omita de elaborar os demais planos anuais cabíveis; determinação de abstenção da União de contingenciar recursos do Fundo. No mérito, 
pugnaram pela confirmação da cautelar, requerendo, ainda que fosse reconhecida a inconstitucionalidade da conduta da União, tanto na condução do Fundo Clima, como na adoção das medidas de proteção ambiental pertinentes à mitigação de mudanças climáticas.

Ao decidir os pedidos cautelares, o ministro Roberto Barroso aduziu que "O quadro descrito na petição inicial, se confirmado, revela a existência de um estado de coisas inconstitucional em matéria ambiental, a exigir providências de natureza estrutural. Afirmou ainda que "a proteção ambiental não constitui uma opção política, mas um dever constitucional".

Isso vai ao encontro do posicionamento do ministro que, recentemente, em texto de sua autoria, manifestou-se acerca da importância da proteção eficaz do meio ambiente. Especialmente sobre a Amazônia, Barroso e Mello (2020, p.36):

Existe uma lógica econômica e social na devastação da floresta. É uma lógica perversa, mas poderosa. Para que ela seja derrotada, é necessário um modelo alternativo consistente, capaz de trazer desenvolvimento sustentável, segurança humana e apoio da cidadania. A ignorância, a necessidade e a omissão estatal são os inimigos da Amazônia. A ciência, a inclusão social e a conscientização da sociedade serão a sua salvação.

Superadas essas premissas e conceituações inaugurais, deve-se enfrentar o problema da pesquisa: é possível pensar na existência de um estado de coisas constitucional ambiental no contexto da ADO 60? E o enfrentamento se dá sob uma dupla perspectiva, visto que a resposta positiva depende da conformação tanto em um filtro teórico quanto prático.

No primeiro ponto, importante ressaltar que já há doutrina que trabalha a possibilidade de se pensar em um estado de coisas inconstitucional ambiental, de modo que não se encontra a proposta da pesquisa isolada no âmbito acadêmico.

Para Caúla e Rodrigues (2018, p.17), por exemplo, “A aplicação do Estado de Coisas Inconstitucional Ambiental pode ser o remédio preventivo para a má gestão administrativa pública ambiental". Afirmam ainda que é lícito ao Judiciário utilizar-se da ferramenta do estado de coisas inconstitucional com o intuito de "reforçar o comprometimento dos governos locais (estados e municípios) na prossecução de suas funções [...] para o restabelecimento do ambiente e da qualidade de vida da população local (CAÚLA; RODRIGUES, 2018, p. 17).

Para Caúla e Queiroz (2018, p. 16), o problema da gestão pública ambiental não se limita ao âmbito legislativo, exemplificando que que o licenciamento ambiental não conseguiu ainda reduzir problemas ambientais a exemplo das escolhas ineficientes relacionadas às obras 
públicas feitas em desacordo com os parâmetros ambientais. Afirmam que os debate acerca do "Estado de Coisas Inconstitucional Ambiental nasce a partir da inobservância do Poder Executivo (federal, estadual e municipal) aos graves riscos ambientais e suas irreversíveis consequências danosas à natureza e à sociedade" $(2018$, p. 16)

Esse entendimento é corroborado por Garcia e Girardi (2017, p. 462) que defendem a tese segundo a qual: "uma vez demonstrado que o meio ambiente está dentro do contexto do Direito Ambiental, existe a possibilidade de declaração do "Estado das Coisas Inconstitucional", desde que o caso in concreto seja de degradação massiva de direitos fundamentais no âmbito do meio ambiente."

E essa parece ser a interpretação mais correta: não há qualquer contradictio in adecto entre o conceito de estado de coisas inconstitucional e a tutela do meio ambiente, especialmente porque, conforme ensina Souza (2016), a proteção ao meio ambiente deve ser percebida enquanto condição de perpetuação e possibilidade da vida humana e não humana.

O desafio, então, é de ordem prática, ou seja, consiste em verificar se há a presença dos requisitos necessários ao reconhecimento do estado de coisas inconstitucional, que, conforme já mencionado, são: a) situação de violação generalizada de direitos fundamentais ambientais; b) inércia ou incapacidade reiterada e persistente das autoridades públicas em modificar a situação; c) a superação das transgressões exigir a atuação não apenas de um órgão, e sim de uma pluralidade de autoridades.

Nesse ponto, não são necessárias muitas digressões para se perceber que é possível, sim, encarar o cenário de (falta) de proteção ambiental como um estado de coisas inconstitucional. Primeiro, a partir da análise do direito dos desastres ambientais.

Aponta-se, a título ilustrativo, os casos de contaminação por chumbo em Santo Amaro - BA, na década de 1960, além do rompimento da barragem do Fundão-MG, que acarretou o vazamento de 35 milhões de litros de rejeitos de minério. Mas são muitos os exemplos de recentes desastres ambientais dos últimos anos, conforme pesquisa do COC by Pearson (2019, recurso online).

No ano de 200 ocorreram vazamentos de óleo na Baía de Guanabara - RJ e nos rios Barigui e Iguaçu - PR. Somados, foram quase seis milhões de litros de óleo que contaminaram as águas, comprometendo seriamente o ecossistema, além de prejudicar diretamente a economia de subsistência de milhares de pescadores. 
Em 2015, ocorreu um incêndio nos tanques de combustíveis do Terminal Químico de Aratu, da empresa Ultracargo, no Porto de Santos. O episódio, apontado como maior incêndio da espécie no Brasil, trouxe severos prejuízos ao meio ambiente: os bilhões de litros de água utilizados no controle das chamas voltaram às aguas, o que ocasionou a redução drástica da quantidade de oxigênio e a elevação da temperatura em $7^{\circ} \mathrm{C}$, levando à morte de nove toneladas de 142 espécies de peixes.

No mesmo ano, ocorreu, na cidade de Mariana-MG, o rompimento das barragens do Fundão e de Santarém, ambas da mineradora Samarco. O episódio trouxe consequências catastróficas: 600 famílias ficaram desalojadas, ao menos 19 pessoas morreram e 1469 hectares de vegetação foram comprometidos. Além disso, aproximadamente 663 quilômetros de rios e córregos foram contaminados pela lama. Poucas horas após o rompimento, a massa de rejeitos chegou ao rio Doce, a maior bacia da região sudeste brasileira, o que ocasionou a morte de toneladas de peixes e outros animais da região. Ao total, foram 43 milhões de metros cúbicos de rejeitos lançados no ambiente.

Não muito tempo depois, em 2019, ocorreu outro desastre em Minas Gerais: o rompimento da barragem de Brumadinho, que levou consigo centenas de vidas. Segundo o IBAMA, os rejeitos de minério devastaram 133,27 hectares de vegetação nativa na Mata Atlântica e 70,65 hectares de Áreas de Preservação Permanente, além de ter contaminado gravemente o Rio Paraopeba, afluente do Rio São Francisco.

Em 2019, houve ainda um episódio de derrame de petróleo cru que atingiu mais de 2 mil quilômetros do litoral das regiões Nordeste e Sudeste.

E não são apenas desastres episódios que demonstram que, de fato, há um cenário de estado de coisas inconstitucional ambiental: o descaso com a proteção do meio ambiental é fator constante que impera na cultura da sociedade. Nesses termos é que Souza (2012, p. 2) menciona que "a Sociedade Mundial está carente de um "upgrade" civilizatório. As últimas gerações são devedoras de um efetivo avanço do que se poderia chamar de um mundo solidário e humanizado" e ainda "o fato de os problemas ambientais e os riscos decorrentes terem crescido a passos agigantados e a sua lenta resolução ter se tornado de conhecimento público pelo seu impacto aumenta a importância da educação ambiental nas suas diversas dimensões" (SOUZA, 2012, p. 7).

No mesmo sentido, Boaventura de Souza Santos afirma que "a crise ambiental decorre diretamente da transnacionalização da pobreza, da miséria e da fome” (2001, p. 42). 
Voltando a Barroso e Mello (2020), tem-se que uma das principais preocupações atuais deve ser a mudança climática, o aquecimento global e a extinção de espécies, o que não são meras conjecturas, mas fatos cientificamente comprovados.

Informam os autores (2020, p. 33) que em 2004 a Amazônia brasileira atingiu o ápice de desmatamento e degradação, tendo a destruição da floresta, nesse ano, atingido $27.772 \mathrm{~km}^{2}$. Que até 2014 houve uma redução desses índices, mas que, a partir de 2015 observou-se novo aumento progressivo, o que pode sinalizar "o arrefecimento do ímpeto governamental no monitoramento, fiscalização e repressão de atividades ilícitas envolvendo a floresta" (BARROSO; MELLO, 2020, p. 35).

Atualmente, o cenário é de desmatamento, queimadas, extração clandestina de maneira, mineração ilegal, além da grilagem das terras públicas.

Por fim, deve-se destacar que recentemente (julho de 2020) o Brasil foi denunciado perante a Comissão Interamericana de Direitos Humanos pela ausência de práticas de medidas que evitem a propagação do coronavírus, especialmente em relação às populações indígenas, o que, ainda que indiretamente, é mais um sinal no sentido de que se está diante de um estado de coisas inconstitucional em matéria ambiental.

\section{CONSIDERAÇÕES FINAIS}

Como primeiro topo argumentativo da pesquisa tem-se o estado de coisas inconstitucional, utilizado para demonstrar a existência de um quadro sistemático de não gozo dos direitos fundamentais (litígio estrutural), especialmente em relação a pessoas e grupos vulnerabilizados, o que reclama, para a sua superação, a atuação estratégica de diversos poderes e instituições (remédio estrutural).

Prosseguindo), apresenta-se o meio ambiente sob à ótica do direito da sustentabilidade. A partir de uma leitura constitucionalizada e convencional, percebe-se que há dever jurídico e não recomendação, conselho ou diretriz - de proteção ao meio ambiente, valendo o postulado que veda a suas proteção deficiente (untermassverbot).

Isso porque o meio ambiente, visto pela matiz do direito da sustentabilidade, é condição de possibilidade e perpetuação da vida humana e não humana. Sua proteção é necessária para o gozo de um rol mínimo de direitos para as presentes e futuras gerações, colocando em xeque, 
como mencionado, os próprios direito à vida, direito à igualdade, liberdade, propriedade etc.

Esses são os contornos teóricos, coligidos a partir da utilização do método indutivo na fase de investigação, aliado às técnicas do referente, da categoria e do fichamento, que autorizaram a síntese da pesquisa.

Diante do exposto, a partir da base indutiva também na fase de interpretação dos dados, chegou-se às seguintes considerações.

O estado de coisas inconstitucional é excepcionalidade. Seu reconhecimento visa impor a todos os Poderes e instituições constitucionais (a exemplo da Defensoria Pública e da Advocacia Pública) a atuação coordenada a fim de superar um estado generalizado de não direito.

Em relação ao meio ambiente, não há contradictio in adjecto, de sorte que, no plano teórico é plenamente possível defender a existência de um estado de coisas inconstitucional, fundamentada na inexistência de um projeto de governança e gestão pública ambiental efetiva. Já existe - ainda que tímida - doutrina nesse sentido. Isso é corroborado, de mais a mais, pela leitura da sustentabilidade, que torna certo o dever jurídico, nacional e transnacional, público e privado, individual e coletivo, de proteção ao meio ambiente.

O desafio, então, é de ordem prática: verificar se os pressupostos para o reconhecimento do estado de coisas inconstitucional estão presentes em relação à (ausência de) proteção ambiental.

Nesse ponto tampouco há divergências: a série recente de desastres ambientais, aliada à prática reiterada da violação dos bens ambientais (a exemplo do desmatamento da Amazônia, que continua sendo vista enquanto mercadoria) e a falta de políticas públicas de governança ambiental no combate às alterações climáticas, conforme denunciado no bojo da Ação Direta de Inconstitucionalidade por Omissão $n^{\circ} 60$, tornam evidente de que, há, de fato, um estado de coisas inconstitucional em matéria ambiental.

Daí porque a necessidade de se pensar o direito à sustentabilidade coletivamente (no âmbito de todos os Poderes e instituições essenciais, além do setor privado e dos atores transnacionais e da coletividade), a fim de dar uma resposta a essa situação de não direito ambiental que atualmente se reconhece, superando, assim, o estado de coisas inconstitucional ambiental. 


\section{REFERÊNCIAS}

BARROSO, Luís Roberto; MELlO, Patrícia Perrone Campos. Como salvar a Amazônia: por que a floresta de pé vale mais do que derrubada In: Revista de Direito da Cidade. vol. 12., $\mathrm{n}^{\circ}$ 2. ISSN 2137-7721, 2020, о. 331.

BENJAMIN, Antônio Herman. Constitucionalização do ambiente e ecologização da Constituição brasileira. In: CANOTILHO, José Joaquim Gomes; LEITE, José Rubens Morato (coords). Direito Constitucional Ambiental brasileiro. São Paulo: Saraiva, 2007, p. 57/58

CAMPOS, Carlos Alexandre de Azavedo. O Estado de coisas inconstitucional e o litígio estrutural. Disponível em: https://www.conjur.com.br/2015-set-01/carlos-campos-estadocoisas-inconstitucional-litigio-estrutural\#_ftnref6. Acesso em: 20 ago 2020.

CAÚLA, Bleine Queiroz; RODRIGUES, Francisco Lisboa. O estado de coisas inconstitucional ambiental. In: Revista de Direito Público Contemporâneo. Instituto de Estudios Constitucionales da Venezuela e Universidade Federal Rural do Rio de Janeiro do Brasil, a. 2, v.1., 2, p. julho/dezembro, 2018.

FERRAJOLI, Luigi. A democracia através dos direitos: o constitucionalismo garantista como modelo teórico e como projeto político. Tradução de Alexander Araújo de Souza et al. São Paulo: Revista dos Tribunais, 2015.

GARCIA, Denise Schmitt Siqueira; SOUZA, Maria Claudia da Silva e; VIEIRA, Ricardo Stanziola (orgs). As dimensões transnacionais do direito ambiental: interfaces da governança ambiental. Disponível em: ajufesc.org.br/wp-content/uploads/2017/02/JéssicaGirardi-e-Denise-Schmitt-Siqueira-Garcia.pdf. Acesso em: 20 ago 2020.

MENDES, Gilmar Ferreira. Os Direitos Fundamentais e seus múltiplos significados na ordem constitucional. In: Revista Jurídica Virtual, Brasília, vol. 2, n. 13, junho/1999. Disponível em: . Acesso em: 21 ago. 2020. 
MORIN, Edgar. A cabeça bem-feita: repensar a reforma, reformar o pensamento. tradução Eloá Jacobina. - 8a ed. - Rio de Janeiro: Bertrand Brasil,2003.

PRINCIPAIS DESASTRES AMBIENTAIS NO BRASIL. Disponível em: https://www.coc.com.br/blog/soualuno/geografia/principais-desastres-ambientais-no-brasil. Acesso em: 20 ago 2020.

RÊGO, Carolina Noura de Moraes. Estado de Coisas Inconstitucional. Rio de Janeiro: Lumen Júris, 2020.

SANTOS, Boaventura de Souza. Pela mão de Alice: o social e o político na pós-modernidade. São Paulo: Cortez, 2001. p. 42

SOUZA, Maria Cláudia da Silva Antunes de. 20 anos de sustentabilidade: reflexões sobre avanços e desafios. In: DESAFIOS. Revista da Unifebe (Online) 2012; 11 (dez):239-252. ISSN 2177-742X

. Sustentabilidade corporativa: uma iniciativa de cunho social transformando o meio ambiente. Revista Jurídica. Unicuritiba . vol. 04, n . 45, Curitiba, 2016. pp.245-262

SUPREMO TRIBUNAL FEDERAL. Decisão cautelar na Ação Direta de Inconstitucionalidade por omissão $\mathbf{n}^{\mathbf{0}} \mathbf{6 0}$ Disponível em: http://www.stf.jus.br/arquivo/cms/noticiaNoticiaStf/anexo/ADO60Decisa771oaudie770nciap u769blica.pdf. Acesso em 21 set 2020. 